\title{
FACTORS ASSOCIATED WITH COMMON MENTAL DISORDERS AMONG WOMEN OF REPRODUCTIVE AGE IN SUMAILA LOCAL GOVERNMENT AREA, KANO STATE
}

\author{
${ }^{1}$ Haddad, M. M., ${ }^{1}$ Ojukwu, A. I., ${ }^{1}$ Mansur, B. Y., ${ }^{1}$ Yunusa, U., ${ }^{1}$ Umar, B. L., ${ }^{1}$ Bilkisu, U. B., *2Murtala, H.H. \& \\ ${ }^{2}$ Muhammad, U. I. \\ ${ }^{1}$ Department of Nursing Sciences, Faculty of Allied Health Sciences, College of Health Sciences, Bayero University Kano \\ ${ }^{2}$ School of Nursing, College of Nursing and Midwifery, Birnin-Kudu, Jigawa State. \\ *Corresponding Authors email: murtalahh@gmail.com, +2348060102360
}

\begin{abstract}
The study was conducted to evaluate the factors associated with common mental disorders among women of reproductive age in Sumaila Local Government Area of Kano state. Cross-sectional descriptive design was used. A total of 163 women were recruited for the study using multi-stage sampling technique. A close-ended structured questionnaire was used for data collection. Data collected were organized and analyzed with Statistical Package for the Social Sciences (SPSS) version 20.0 and results were presented using frequency distribution and percentages, and mean \pm standard deviation. Chi-square analysis was used to test for association between factors associated with and development of common mental disorders at $5 \%$ level of significant within 95\% confidence interval. Findings from the study revealed that $28.4 \%$ of the respondents had Common Mental Disorders, awareness of the respondents were low as most of them believed that demonic possession (73.5\%) and witchcraft (58.6\%) were the causes of mental illness. Significant association was found between factors associated with common mental disorders and age at first marriage $\left(\chi^{2}=3.395, \mathrm{p}=0.048\right)$ and low social integration $\left(\chi^{2}=5.414, \mathrm{p}=0.020\right)$, of the women. The study concluded that common mental disorders in rural communities are mostly related to age at first marriage It is recommended that mental health personnel should conduct advocacy to traditional and religious leaders, also the male parents in rural areas on the influence of early marriage on mental disorders and clear their misconceptions on its causes, for early prevention and improved mental health seeking behaviour.
\end{abstract}

Keywords: Awareness, Common mental disorders, Factors, Rural community, Women of reproductive age

\section{INTRODUCTION}

Mental disorders are among the most important public health issues as it contributes to $14 \%$ of the global burden of disease (Abraham et al., 2018). The term Common Mental Disorders was coined by Goldberg and Huxley to describe commonly encountered disorders in community and primary-care settings, and whose occurrence signals a breakdown in normal functioning (Husain et al., 2016).

Gender influence the occurrence of mental disorders, in which, women are more likely than men to develop the disorders (Ansuman et al., 2014; Sathyanarayana \& Manjunatha, 2019). Women were found to have two to three times more risk than in males; higher risk is seen among divorced or widowed female or those who were exposed to intimate-partner violence (Husain et al., 2016; Kingsbury, 2017). In Nigeria, an estimated $20 \%-30 \%$ of our population are believed to suffer from mental disorders and more than half of this percentage is reported to be women (Onyemelukwe, 2016). The percentage is quite significant in an estimated population of over 200 million. Unfortunately, the attention given to mental health issues in Nigeria is so minimal, results in empirically poor the level of awareness among public and give more rooms for the misconceptions of mental health issues to continue to flourish in $21^{\text {st }}$ century (Suleiman, 2016). Moreover, people living in rural communities have acute shortage of mental health professionals and limited access to mental health care services, thus, women living in rural areas with low education levels are less likely to seek care for mental illnesses due to the relatively low levels of awareness about mental disorders compared to women living in urban areas (Ajay, 2012; Parreira et al., 2017). Moreover, women experiences marginalization and poverty are at greater risk of having mental disorders (Ajay, 2012; Centre for Disease Control, 2017). Also, the World Health Organisation (2018) reported that, national policies, social protection, standards of living, working conditions, and community support, stress, hereditary, nutrition, perinatal infections and exposure to environmental hazards are determinants of mental health and mental disorders.

There are various bio-psycho-social factors increase the vulnerability of women to poor mental health as a result of multiple points of intersection between mental health and 
reproductive health (Sathyanarayana \& Manjunatha, 2019). Maternal mental health problems are often under diagnosed with core features such as tiredness or poor sleep being interpreted as within societal expectations of motherhood. The risks of Common mental disorders however are significant and may contribute to self-neglect and higher rates of physical illness, as well as suicidal tendencies (Husain et al., 2016).

The awareness about mental health or mental illness and the interpretation varies from culture to culture. In spite of these, lack of public knowledge concerning mental illnesses, and the help-seeking behaviour of mentally ill person is widely affected by public awareness about mental illnesses (Kabir et al., 2004). Moreover, people have various beliefs on the causes of mental illnesses. According to Chikomo (2012) reported possession of evil, witchcraft, or curse, Khan et al. (2011) added supernatural agents. Read and Doku (2012) reported that anxiety, tension, feeling of guilt and selfreproach, feelings of sadness and loss of interest and enjoyment. Kabir et al. (2004) added that aggression/destructiveness, loquaciousness, eccentric behaviour and wandering as the clinical features of mental illness with the respondents opted for orthodox medical care.

In addition to rural labour, these women often do the household work, in fact, that may worsen their physical and mental conditions. Therefore, it is essential to value the health of the rural population considering their different life and work conditions. Common mental disorders are the frequently seen mental health problems in the community and primary health care, and most of the researches are conducted in hospitals or schools leading to a dearth in studies conducted in the community (Forte et al., 2008; Husain et al., 2016; Kingsbury, 2017; Tessema et al., 2019; Negash et al., 2020). In line with this, the study sort to identify the incidence of common mental disorders, factors associated with common mental disorders and awareness of common mental disorders among women of reproductive age in Sumaila Local Government Area of Kano State.

\section{MATERIALS AND METHODS}

Study setting: The study was conducted in Sumaila Local Government Area, in Kano State with headquarters in Sumaila. Sumaila Local Government Area is located within the Kano South Senatorial District with an area of $1,250 \mathrm{~km}^{2}$. The local government area is bounded to the north by Garko local government area, to the east by Takai local government area, to the south by Bauchi State, and to the west by Tudun Wada local government area. Districts and wards under Sumaila are Sitti, Masu, Magami, Kanawa, Gediya, Gani, Gala, Rimi, Sumata, Rumo, Sumaila and Garfa

Research design: A cross sectional descriptive research method was used to identify the incidence of mental disorders, factors associated with common mental disorders and awareness of common mental disorders among women of reproductive age in Sumaila Local Government Area, Kano State.

Study Population and Sampling: The study population consists of women of reproductive age, between the ages of 16-49 years in Sumaila Local Government Area, Kano State. Women from Sumaila Ward were selected using multi-stage sampling method. Convenient sampling was used to administer the questionnaire.

A total of 163 women were recruited for the study based on common mental disorders prevalence rate of $10.8 \%$ Jenkins $e t$ al., (2012), using the formula $\mathrm{n}=\mathrm{z}^{2} \mathrm{p}(1-\mathrm{p}) / \mathrm{e}^{2}$ (Kirkwood, 2003).

Research Instruments, Validity and Reliability: Youth survey questionnaire was adapted from WHO (2017). The questionnaire was administered to the women of reproductive age. The response rate was $99.38 \%$ (162). Face and content validity of the adapted instrument were assured by the expert in the field. Internal Consistency Reliability was also assessed in which Cronbach's alpha value of 0.75 was obtained.

Data Analysis: Data was analysed using Statistical Package for the Social Sciences (SPSS) software program 20.0 version. The data were summarized using frequency distribution tables and percentages. Mean and standard deviation were used for continuous variables, while frequencies and percentages were employed for discrete variables. Chi-square analysis was used to test for association between factors associated with and development of common mental disorders. Level of significance was set at $5 \%$, within 95\% confidence interval.

Ethical consideration: Ethical approval was given by Kano State Health Management Board and Sumaila Local Government granted approval for the study. An informed consent from the respondents was obtained and confidentiality was assured.

\section{RESULTS}

\section{Socio-demographic Characteristics of Respondents}

Table 1 showed that the mean age of the respondents is 25.77 \pm 7.57 . Majority of the respondents $(61.7 \%)$ practiced Islam as a religion. Majority of the respondents were married $(71.0 \%)$, while $62.3 \%$ had non-formal education. Most (33.9\%) of the respondents were Housewives, some $(25.9 \%)$ Traders, few (14.2\%) were farmers. Most (62.3\%) of the respondents were from monogamous homes while others (37.7\%) were from polygamous homes. Half of the respondents $81(50.0 \%)$ had a family size of six to ten members. Majority of the respondents $(46.3 \%)$ had an average monthly income of $\angle 2,000$, few of the respondents (9.9\%) had an average monthly income of 6,000 . 
Table 1: Socio-Demographic Characteristics of the Respondents $(n=162)$

\begin{tabular}{|c|c|c|}
\hline Variables & Frequency & Percentages (\%) \\
\hline \multicolumn{3}{|l|}{ Age } \\
\hline \multicolumn{3}{|l|}{ Mean (25.77 years) } \\
\hline \multicolumn{3}{|c|}{ Standard Deviation $( \pm \mathbf{7 . 5 7})$} \\
\hline \multicolumn{3}{|l|}{ Religion } \\
\hline Islam & 100 & 61.7 \\
\hline Christianity & 60 & 37.2 \\
\hline Others & 2 & 1.1 \\
\hline \multicolumn{3}{|l|}{ Marital Status } \\
\hline Single & 39 & 24.1 \\
\hline Married & 115 & 71.0 \\
\hline Divorced & 3 & 1.9 \\
\hline Widowed & 5 & 3.1 \\
\hline \multicolumn{3}{|l|}{ Educational Status } \\
\hline Non Formal Education & 101 & 62.3 \\
\hline Primary & 18 & 11.1 \\
\hline Secondary & 29 & 17.9 \\
\hline Tertiary & 14 & 8.6 \\
\hline \multicolumn{3}{|l|}{ Occupation } \\
\hline Housewife & 55 & 33.9 \\
\hline Trader & 42 & 25.9 \\
\hline Farmer & 23 & 14.2 \\
\hline Student & 20 & 12.3 \\
\hline Civil Servant & 14 & 8.6 \\
\hline Unemployed & 5 & 3.1 \\
\hline Others & 3 & 1.8 \\
\hline \multicolumn{3}{|l|}{ Family Type } \\
\hline Monogamous & 101 & 62.3 \\
\hline Polygamous & 61 & 37.7 \\
\hline \multicolumn{3}{|c|}{ Average Monthly Income (Naira) } \\
\hline Less Than 2,000 & 75 & 46.3 \\
\hline $3,000-5,000$ & 62 & 38.3 \\
\hline $6,000-10,000$ & 16 & 9.9 \\
\hline $11,000-20,000$ & 5 & 3.1 \\
\hline 20,000 And Above & 4 & 2.5 \\
\hline
\end{tabular}




\section{Incidence of Mental Illness}

Table 2 showed that less than three quarter of the respondents $116(71.6 \%)$ Do not have common mental disorder while greater than one quarter of the respondents 46 (28.4\%) have common mental disorders.

Table 2: Incidence of Mental Illness $(n=162)$

\begin{tabular}{lcc}
\hline Variable & Frequency & Percentage \% \\
\hline & & 71.6 \\
Absence of Mental Disorder & 116 & 28.4 \\
Presence of Mental Disorder & 46 & \\
\hline
\end{tabular}

Relationship Between Factors Associated with and Development of Common Mental Disorders

Table 3 showed that majority of the respondents indicated that, substances abuse (84.8\%), less than seventeen years as the age of first marriage $(52.2 \%)$, and poor living condition (56.5\%) as factors associated with common mental disorders. Statistically significant association was found between factors associated with common mental disorders and age at first marriage $\left(\chi^{2}=3.395, \mathrm{p}=0.048\right)$ and low social integration $\left(\chi^{2}=5.414, \mathrm{p}=0.020\right)$, of the women.

Table 3: Relationship Between Factors Associated with and Development of Common Mental Disorders $(\mathbf{n}=162)$

\begin{tabular}{|c|c|c|c|c|}
\hline Factors & Frequency & Percentage (\%) & $\chi^{2}$ & P Value \\
\hline \multicolumn{5}{|l|}{ Substance Ever Used } \\
\hline Never Ever Used & 39 & 84.8 & & \\
\hline Alcohol Ever Used & 4 & 8.7 & 4.338 & 0.227 \\
\hline Marijuana Ever Used & 2 & 4.3 & & \\
\hline Alcohol and Marijuana Ever Used & 1 & 2.2 & & \\
\hline \multicolumn{5}{|l|}{ Substance Currently Used } \\
\hline Not Used at All & 39 & 84.8 & & \\
\hline Alcohol & 5 & 10.9 & 6.524 & 0.089 \\
\hline Marijuana & 2 & 4.3 & & \\
\hline \multicolumn{5}{|l|}{ Age at First Marriage } \\
\hline Not Ever Married & 9 & 19.6 & & \\
\hline$\leq 17$ Years & 24 & 52.2 & 3.395 & 0.048 \\
\hline$\leq 18$ Years & 13 & 28.3 & & \\
\hline \multicolumn{5}{|l|}{ Clinical Characteristics } \\
\hline Chronic Medical Illness & 13 & 28.3 & 0.543 & 0.762 \\
\hline Family History of Mental Illness & 12 & 26.1 & 2.006 & 0.157 \\
\hline \multicolumn{5}{|l|}{ Socio Economic Factors } \\
\hline Poor Living Conditions & 26 & 56.5 & 0.424 & 0.515 \\
\hline Inability to Have Three Square Meals & 19 & 41.3 & 1.549 & 0.213 \\
\hline Inability to Make Decisions Independently & 13 & 28.3 & 3.457 & 0.063 \\
\hline Low Family Support & 12 & 26.1 & 2.006 & 0.157 \\
\hline Low Social Integration & 13 & 28.3 & 5.414 & 0.020 \\
\hline \multicolumn{5}{|l|}{ Intimate Partner Violence } \\
\hline Does Your Husband Beat You & 5 & 10.9 & 0.198 & 0.656 \\
\hline
\end{tabular}




\section{Respondents' Awareness on Common Mental Disorders}

Majority of the respondents 121(74.7\%) believed that mental illness is a condition where a person wears tattered clothes and eats rubbish from the streets. Most of the respondents believed that demonic possession 119(73.5\%) and witchcraft 95(58.6\%) were the cause of mental illness. Most of the respondents agreed that coming out naked (74.1\%), and dressing in rags (66.0\%) were critical signs of mental illness. Most of the respondents preferred hospital (61.7\%) and traditional healers (31.5\%) as the preferred place for mental illness treatment. Although, their major sources of information were peer group (59.9) and mass media $(31.5 \%)$.

Table 4: Respondents' Awareness on Common Mental Disorders $(n=162)$

\begin{tabular}{lcc}
\hline Variables & Frequency & Percentage (\%) \\
\hline Mental Illness Means? & & 74.7 \\
A condition where a person wears tattered clothes and eats refuse from the & 121 & \\
streets & & 25.3 \\
A set of condition that affects a person's temper, thoughts and behaviour & 41 & 29.6 \\
Causes of Mental Illness: & & 35.8 \\
Drug Abuse & 48 & 34.0 \\
Family Issues & 58 & 4.3 \\
Loss of Loved Ones & 55 & 58.6 \\
War & 7 & 73.5 \\
Witchcraft & 95 & 13.0 \\
Demonic Possession & 119 & 0.6
\end{tabular}

Can An Individual Be Born With Mental Illness

\section{Signs of Mental Illness:}

Dressing in Rags

Always Locked Up Inside

Behaving Confused

Lack of Interest in What the Individual Enjoyed Before

Talking To Themselves All The Time

Coming Out Naked

Lack of Respect to Elders

Others

Preferred Place for Treatment of Mental Illness

Hospital

Mosque

Church

Chemist

At Home

Traditional Healer

They Cannot be treated

Source of Information

Peer group

Mass Media 


\section{DISCUSSION}

Majority of the respondents were at youthful age (15-25 years). This could be attributed to the fact early that marriage is common among the rural communities in the northern Nigeria. Majority of the respondents were Muslims with nonformal level of education. This is due to the fact that, Islamic is the predominant religion in the region and girl-child education has not really gained sway in the rural, northern communities of Nigeria.

Findings from this study indicated that, there are women of reproductive age with mental disorders in the study setting. The finding is similar to the study conducted in Ethiopia by Abraham et al. (2018). However, contrasting findings were reported in Lagos, south west Nigeria by Jenkins et al. (2014). This could be attributed to the fact that these respondents had a high level of education and a good health seeking behaviour.

The result of this study revealed that, substances abuse, less than seventeen years as the age of first marriage, poverty, chronic medical illness and poor living condition as the major factors associated with common mental disorders. The study report is in line with the findings Ajay (2012) and Daud et al. (2008) who identified poverty, while Husain et al. (2016) reported chronic physical illness and poor living conditions. Also, Farah et al. (2011) and Abraham et al. (2018) variously reported early age at first marriage as the factor associated with common mental disorders. The study findings also revealed that, there is statistically significant association between factors associated with common mental disorders and age at first marriage $\left(\chi^{2}=3.395, \mathrm{p}=0.048\right)$ and low social integration $\left(\chi^{2}=5.414, \mathrm{p}=0.020\right)$, of the women. The study report conforms to the finding of Patel et al. (2006) in Pakistan who identified that there was significant association of being married at earlier age and Common mental disorders. This could be due to the fact that, early pregnancy poses great health risks for young women and these risks are exacerbated by inadequate access to maternal and child health services, inadequate mental health workers, irregular income, financial and educational disadvantages and having more children. Also, Winters et al. (2010) reported that low social integration is related to the mental health development. This is factual because women could easily develop depression as a result of isolation, being unhappily married, and as a complete house wife.

Majority of the respondents believed that mental illness is a condition where a person wears tattered clothes and eats refuse from the streets. This shows that respondents have limited awareness about meaning of mental illness as their preferred option only seen when condition became chronic. Most of the respondents believed that demonic possession, Loss of Loved Ones, family problems and witchcraft were the cause of mental illness. The study report is in line with the findings of Chikomo (2012) and Khan et al. (2011) who variously reported possession of evil, witchcraft and supernatural agents as the causes of mental illness. This revealed respondents' poor awareness on the causes of mental illness ranges from hereditary, social, psychological, emotional and environmental. Most of the respondents agreed that coming out naked and dressing in rags were critical signs of mental illness. This could be due to the fact that most respondents have non-formal education. The findings are not in line with the result of Kabir et al. (2004) who reported that aggression/destructiveness, loquaciousness, eccentric behaviour and wandering as the clinical features of mental illness. Most of the respondents preferred hospital and traditional healers as the preferred place for mental illness treatment. Kabir et al. (2004) in their study reported that respondents opted for orthodox medical care when asked about their preferred treatment option. Although, this study reported that, the major sources of information were peer group and mass media. This is factual because the women were rural dwellers and have no access to or failed to be enrolled in formal educational system.

\section{CONCLUSION}

There is presence of mental disorder in the community which is connected to substances abuse, years as at the age of first marriage, poverty, chronic medical illness and poor living condition as the major factors associated with common mental disorders. This is a huge gap to health workers and policy makers in advocating, planning and provision of care to the populace. This could also affect reportage of the disorder and influence the health-seeking behaviour of the community.

\section{REFERENCES}

Abraham, Y., Yigzaw, N. and Zewde, F. (2018). Factors Associated with Common Mental Disorders among Women of Reproductive Age Group at Arbaminch Town, Southern Ethiopia: Cross Sectional Study. Journal of Psychiatry, 21(2): 1-6.

Ajay, R. R. (2012). Mental Health Disorders. Kathmandu University Medical Journal, 5(1): $\quad$ 214-219.

Alem, A., Kebede, D., Jacobsson, L., Woldesemiat, G. and Kullgren, G. (2014). Prevalence and Socio-Demographic Correlates of Mental Distress in Butajira, Ethiopia. Acta Psychiatrica Scandinavica Supplication, 3(2): 48-55.

Ansuman, P., Aditya, P.P. and Madhulita, P. (2014). Mental Health Status among Married Working Women Residing in Bhubaneswar City, India: A Psychosocial Survey. Biomed Research International, 4:1-7.

Centre for Disease Control. (2017). Mental Health among Women of Reproductive Age. National Center for Chronic Disease Prevention and Health Promotion Division of reproductive health, 2-4. from https://www.wvdhhr.org/wvhomevisitation/prenatal/Mental_ Health_Women_Repo_A ge.pdf 
Chikomo, J.G. (2011). Knowledge and attitude of Kinondoni community towards mental illness. Journal of Mental Health, 14:167-181.

Daud, S., Rootaba, K. and Aftab, A. (2008). Prevalence, Predictors and Determinants of Depression in Women of the Reproductive Age Group. E:/Biomedica, 24: 18-21.

Farah, Q., Murad, M.K., Girmay, M. and Martin, P. (2011). Male Gender Preference, Female Gender Disadvantage as Risk Factors for Psychological Morbidity in Pakistani Women of Childbearing Age - A Life Course Perspective. BMC Public Health, 11(1):745-9.

Fortes S., Villano, L.A.B. and Lopes, C.S. (2008). Nosological Profile and Prevalence of Common Mental Disorders of Patients Seen at the Family Health Program (FHP) Units in Petrópolis, Rio de Janeiro. Brazilian Journal of Psychiatry, 30(1): 21-29.

Husain, N., Mukherjee, I., Notiar, A., Alavi, Z., Tomenson, B., Hawa, F., Malik, A., Ahmed, A. and Chaudhry, N. (2016). Prevalence of Common Mental Disorders and its Association with Life Events and Social Support in Mothers Attending a Well-Child Clinic: Findings from Mombasa, Kenya. SAGE Open, 6(4):1-6.

Jenkins, R., Njenga, F., Okonji, M., Kigamwa, P., Baraza, M., Ayuyo, J., Singleton, N., McManus, S. and Kiima, D. (2012). Prevalence of Common Mental Disorders in a Rural District of Kenya, and SocioDemographic Risk Factors. International Journal of Environmental Research and Public Health, 9(5): 18101819.

Kabir, M., Iliyasu, Z., Abubakar, I.S. and Aliyu, M.H. (2004). Perception and Beliefs About Mental Illness Among Adults in Karfi Village, Northern Nigeria. BMC International Health and Human Rights; 4(3):31-9.

Khan, T.A., Hassali. H. and Tahir. Khan. A., (2011). A Pilot Study Evaluating the Stigma and Public Perception About Causes of Depression and Schizophrenia. Iranian Journalpublic health, 40(1):50-56.

Kingsbury, A. M. (2017). Women's Mental Health Following the Birth of a Child: A Life Courses Approach. The University of Queensland Australia, 1:20-44.

Negash, A., Khan, M.A., Medhin, G., Wondimagegn, D. and Araya, M. (2020). Mental Distress, Perceived Need, and Barriers to Receive Professional Mental Health Care Among University Students in Ethiopia. BMC Psychiatry, 20(1):187194.
Onyemelukwe, C. (2016). Stigma and Mental Health in Nigeria: Some Suggestions for Law Reform. Journal of law Policy Globe, 55:63-68.

Parreira, B. D. M., Goulart, B. F., Haas, V. J., Riul da Silva, S., Monteiro, J. C, S., Gomes- Sponholz, F. A. (2017). Common Mental Disorders and Associated Factors: A Study of Women from a Rural Area. Revista da Escola de Enfermagem da USP, 51:67-77.

Patel, V., Kirkwood, B., Pednekar, S., Pereira, B. and Barros, P. (2006). Gender Disadvantage and Reproductive Health Risk Factors for Common Mental Disorders in Women. Arch Gen Psychiatry, 7(4):404-413.

Read, U.M. and Doku, V.C.K. (2012). Mental Health Research in Ghana: A Literature Review. Ghana Medical Journal, 46(4):29-38.

Sathyanarayana, R. K. and Manjunatha, S. (2019). Common Mental Disorders Among Women of Reproductive Age Group in an Urban Area in Bengaluru. International Journal of Community Medicine and Public Health, 41(4):1768-1773.

Suleiman, E. D. (2016). Mental health disorders in Nigerian: A Highly Neglected Disease. Annals of Nigerian Medicine, 10(2): 47-48

Tessema, T.T., Gebremariam, T.A., Abebe, E.A. and Gebre, R.D. (2019). The Prevalence and Factors Associated with Mental Distress Among College Students in Southern Ethiopia: A Cross-Sectional Study. Ethiopian Journal of Health Sciences, 29(3):353- 360.

Winters, C. A., Cudney, S. and Sullivan, T. (2010). Expressions of Depression in Rural Women with Chronic Illness. Rural Remote Health, 4:1-14.

World Health Organisation. (2018). Mental Health Disorders. Retrieved May 31, 2019, from World Health Organization: http://www.mental disorders who. com

World Health Organization. (2009). Mental Health Aspects of Women's Reproductive Health: A Global Review of Lliterature. Retrieved June 01, 2019, from World Health Organization:http://whqlibdoc.who.int/publications/2009/97 89241563567_eng.pdf. 